apparatus is affected prior to, and to a greater extent than, the cardiac, and Dr. McCardie recently reported a case where the alæ nasi continued to work regularly after the respirations had ceased, and in which instance tracheotomy was performed but without avail. Concerning the diagnosis the base of the tongue affords a more constant and the most tangible evidence-i.e., posterior to the circumvallate papillæ and between these and the epiglottis there are very frequently a great multiplication and hypertrophy of the Iymphatic nodules. If on examination with a forehead mirror and a laryngoscope mirror, this condition is seen, it, per se, would be sufficient to deter me from operating or giving an anæsthetic, and, a fortiori, if considered in conjunction with other probabilities. Unfortunately, the negative phase of this peculiarity is worthless.

ii. The association of epilepsy and hereditary neuropathic taints seems scarcely sufficiently emphasised. Some people, in whom unexpected deaths under anæsthetics have take place and post-mortem examination has subsequently disclosed the status lymphaticus, have previously shown a terrible fear of anæsthetics. Now a marked connexion between this disease and the nervous system is recognised, also the consensus of opinion grants that death can take place in the initial stages of chloroform anæsthesia from fright alone in certain neurotic subjects, and infers that any aromatic vapour believed to be chloroform would have produced the same disaster. Why should not this be another possible explanation of the fatalities, as I particularly notice that the deaths occur only in the lighter stages of anæsthesia, either previously to, or on recovery from, the third stage of narcosis? Even the popular saying is that "Sudden fright takes away one's breath." The status 1 ymphaticus is apparently a disease that has been insidiously at work for an unknown time till some either exceedingly trivial or most serious firing-off cause gives rise to a fulminating termination. The breathing and heart's action more often stop simultaneously, though very frequently the respiratory movements cease first and the heart stops beating secondarily at varying lengths of time subsequent to the stoppage of respiration. The pulse may be perceptible at the wrist just after the cessation of the respiratory movements, but most usually it is not, in which circumstances the heart can often still be heard with a stethoscope over the præcordium to be beating weakly and irregularly. In yet other instances the heart's action must be the first to stop. The cessation apparently takes place during systole, as both ventricular cavities are usually empty post mortem, that of the left side invariably. When the heart stops first, or when both centres appear to be seized at the same time, a sudden and extreme degree of pallor comes over the face; the lips, eyes, and complexion immediately assume an ashen appearance, the pupils dilate, and an obviously cadaverous effect is at once produced, forming what is so-called "the fatal white syncope." When the respiratory centre is affected to a greater extent than the cardiac centre, or prior to it, the face rapidly becomes livid, con. stituting the so called "blue syncope." It seems probable that this is not infrequently recovered from, but in many instances the particular kind of lividity must look ominous from the onset, and although the pupils may only dilate to a small extent the lips assume a leaden hue, giving rise to a general appearance that is quasi-moribund. The actual degree of cyanosis does not help one much and, perhaps, the more marked this is the more one can do by artificial respiration, \&c.

The LANCET and the Hyderabad Commission on Chloroform after extensive experimentation on dogs and monkeys conclude that chloroform will not cause sudden death from stoppage of the heart. That it has no power of increasing the tendency to either shock or syncope during operations, and say further that if shock or syncope from any cause does occur, it prevents, rather than aggravates, the dangers of chloroform inhalation. That in fatty degeneration of the heart, which is very frequently found in subjects of the disease in question, chloroform in no ways endangers it, but, on the other hand, is a positive advantage, by virtue of lowering the blood pressure and lessening the work it has to perform (this result also is not theoretical but has been proved experimentally on dogs). In examining the notes, both ante- and post-mortem, of over 700 deaths under anæsthetics collected by THE LANCET and the Hyderabad Commissions during a period of 60 years, in no one instance is death attributed to the status lymphaticus, although, on reading between the lines of the notes, a very large number of the fatal cases of syncope must surely have been due to this disease.

Reading.

\section{COMPOUND, COMMINUTED, AND DE- PRESSED FRACTURE OF SKULL, WITH LACERATION OF BRAIN AND RUPTURE OF MIDDLE MENINGEAL ARTERY.}

BY ROBERT HILL, M.V.O., M.R.C.S. ENG., L.R.C.P. LOND., TLEET SURGEON, R.N.

A MAN, aged 33 years, a Maltese shipwright, was brought to the Royal Naval Hospital at Malta about midday on Dec. 13th, 1906, with the following history. When working in the rigging of a cruiser in Malta Harbour he fell on to the vertex of his skull, a distance of 12 feet, striking the iron edge of the bridge ladder. He was picked up unconscious and vomited. There were a wound on the top of his head, from which blood and brain matter were escaping, and bleeding from the left ear and nostril.

On examination the patient was seen to be a powerfully built man; he was unconscious but when moved or roused showed reflex irritability. He lay curled up in bed on his left side, with the thighs flexed on the abdomen, the legs on the thighs, the forearms on the arms, and the fists clenched. The pupils were equal and contracted with conjugate deviation of the eyes. There was a jagged wound of the scalp over the anterior part of the left parietal bone near the middle line about one and a half inches long, from which brain matter and blood escaped. There was a distinct depression of the skull at this point. There was no escape of cerebro-spinal fluid from the ear, but there were an extravasation of blood into the left eyelid and dried blood in the left ear and nostril. The temperature was $98^{\circ} \mathrm{F}$., the pulse was small and difficult to count, and the respirations were shallow and rapid. There was no paralysis of the limbs. The entire scalp was shaved and thoroughly cleansed.

At 2 P.M. the patient was taken to the operating-room and an incision was made across the vertex from ear to ear, about one and a half inches posterior to the wound, through the whole scalp, and the anterior flap was reflected over the face. The skull over the anterior portion of the left parietal and frontal bones presented the appearance of a cracked walnut, with the fragments completely fractured and impossible to keep in position, and with a portion about $1 \frac{1}{2}$ inches by 1 inch, irregular in shape, depressed close to the longitudinal sinus, and from the free hæmorrhage it was feared that this structure must be wounded. Brain substance was also exuding. On attempting to elevate this depressed portion it was found that the inner table was much more extensively fractured than the outer one. By removing two smaller fragments close to it the depressed bone was finally removed, when an immediate improvement in his respiration was noticed. The longitudinal sinus was found intact but the hæmorrhage was very serious and coming from the direction of the middle meningeal artery. By this time the patient was blanched and no pulse could be felt at the wrist. Staff-Surgeon H. C. Whiteside injected two pints of saline solution into the left median basilic vein and one pint was injected per rectum. This had an excellent result; the patient rallied, became a better colour, and the pulse could be counted.

In addition to removing the fractured portions of bone, it was found necessary to remove more bone in the direction of the external angular process with gouge forceps to reach the main trunk of the middle meningeal artery which was found ruptured just before its bifurcation. This vessel was underrun and ligatured. In all five pieces of bone were removed, irregular in shape, but measuring roughly nine square inches. The dura mater, which had been severely lacerated, was brought together and sutured, but it was found impossible

1 A paper read before the Malta branch of the United Services Medical Society. 
entirely to cover the area round the depressed portion where the dura mater had been torn away. The whole surface was irrigated with normal saline solution. One small drainage-tube was passed through an incision in the scalp opposite the wounded artery, another through the original wound, and one at each end of the long operation wound which was sutured with silkworm gut. The patient's condition on being put back to bed was better; the pulse was 100 and small, the respirations were 24, the colonr was fair, and the skin was cold. At night his temperature was $102^{\circ}$, the pulse was 110 , and the respirations were 16.

On Dec. 14th the patient's temperature was $99.8^{\circ}$, the pulse was 90 , and the respirations were 18 . He was very restless, irritable, and unconscious and struggled violently when a catheter was passed. On the 15th the temperature was $99 \cdot 8 \circ$, the pulse was 96 , and the respirations were 16 . No squint was present; there was some loss of power in the right arm but there was no paralysis of the face. He was able to take nourishment. He passed urine into a urinal when placed for him and also passed it in bed. The kneejerks were increased. The plantar reflexes were present. On the 16th the temperature was $99 \cdot 4 \circ$, the pulse was 76 , and the respirations were 16 . He recognised his friend this morning. On the 17th the temperature was normal and the pulse was 60. The wound was dressed; it looked clean and there was some serous discharge. All the tubes were removed. The patient asked for a urinal. $\mathrm{He}$ was fairly sensible. From this time his progress was uneventful. He had constant but not very severe headache for two months but no paralysis or loss of sense or memory.

On March 1st, 1907, under ether, a scale of dead bone was removed from the site of the original wound and the bone and tissues were scraped. This wound healed rapidly. A mould was taken of the skull and a silver plate fitted into a cap tightly fitted to the head. The patient left the hospital well on May 3rd. He came to see me a short time ago, 14 months after the operation. He had worked during the hot surnmer months without any headache or inconvenience. $\mathrm{He}$ is as strong as ever and wants more work. He has never had any fits. There is a large amount of fibrous thickening of the tissues of the scalp filling in the cavity in the vertex, but the pulsation of the brain can still be felt on deep pressure. The size of this cavity is roughly 4 inches by 2 inches.

The chief points of interest in this case are: 1 . The extent of the injury to the brain substance without subsequent paralysis or fits and without any hernia cerebri. 2. The immediate improvement in the respiration on removing the depressed bone. 3. The rapid response to the intravenous injection of saline solution when the patient was collapsed from the hæmorrhage.

The accompanying reproduction of a photograph of the patient after recovery shows the deformity left in the skull.

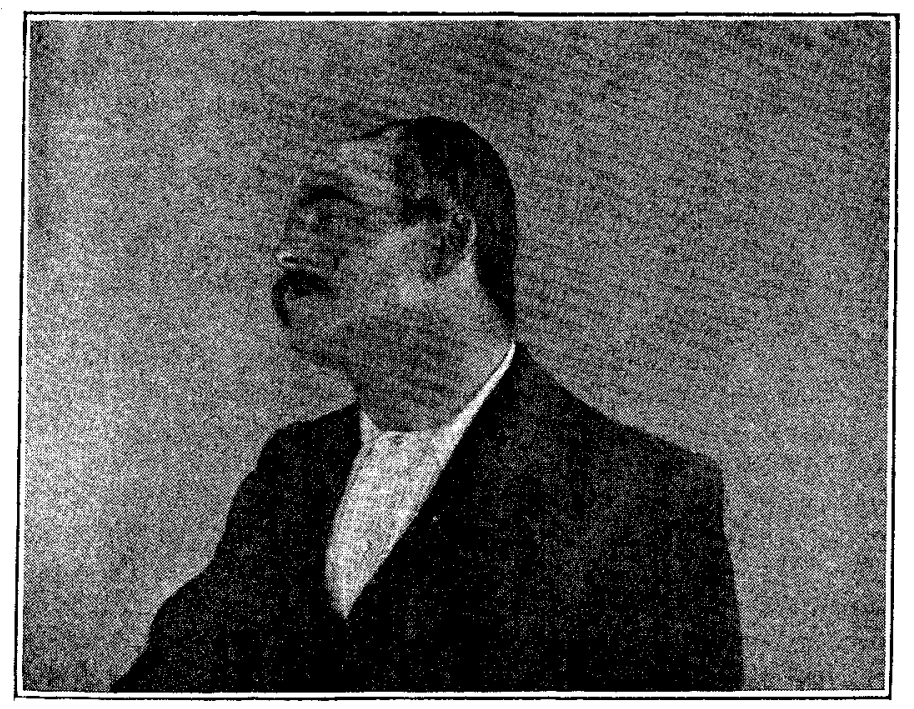

Reprotuction of a photograph of the patient after recovery.

I have to thank Staff-Surgeon Richards for giving chloroform in diflicult circumstanees, and Staff-Surgeon S. H. Woods for assisting me.

Royal Nivial llospital, Malta.

\section{A CASE OF EXTRA-UTERINE GESTATION; OPERATION DURING THE SIXTH MONTH OF PREGNANCY. ${ }^{1}$}

By HERBERT J. PATERSON, M.A., M.B., B.C. CANTAB., F.R.C.S. ENG.,

ASSISTAN'T SURGEON, LONDON TEMPERANCE HOSPITAL, ETC.

THREE years ago I reported to the Obstetrical Society a case of Operation during the Sixth Month of Extra-uterine Pregnancy. ${ }^{2}$ In that case the placenta was removed and the hæmorrhage controlled by the ligation with silk of many vessels and by packing the sac with gauze. The points of interest in that case were: First, that the gestation persisted in spite of two severe and three slight attacks of internal hæmorrhage. Secondly, the difficulty in determining whether the foetus was alive or dead. Thirdly, the severity of the symptoms caused by intestinal toxæmia due to intestinal paresis, the result, as I then thought, mainly of injury of the peritoneal coat of the bowel produced by the separation of adhesions, but which I am now of opinion was due almost entirely to the gauze packing. The paresis was successfully treated by repeated doses of calomel. Fourthly, the prolonged convalescence of the patient, due to the persistence of a sinus. for 18 months, from which ligatures were discharged from time to time. For several months the patient suffered from. abscesses in her neck, probably the result of septic absorption from the persistent sinus. Eventually, however, the patient made a complete recovery, and is at the present time, six and a half years after the operation, enjoying robust health.

A few months back I had under my care a somewhat similar case, of which the following are brief details:-The patient, aged 29 years, suffering from abdominal pain, was admitted into the London Temperance Hospital on March 9th last, under the care of my colleague Dr. J. Porter Parkinson. She had had ten children, of whom five were premature and stillborn. The catamenia had been perfectly regular, the last period having ceased on the day of admission. On admission the patient was extremely anæmic, but. well nourished. The temperature was $100^{\circ} \mathrm{F}$. and the pulse was 116. In the right iliac region reaching inwards beyond the middle line, and to the level of the umbilicus was a smooth, firm, rounded, fixed, tender swelling. Per vaginam there was some fulness in the vaginal roof, the cervix lay to the left, the texture was firm, and the canal was closed. Bimanually the uterus was somewhat large; the abdominal swelling could not be felt in the pelvis but tenderness. prevented a satisfactory examination. I thought that the patient had an ovarian cystoma with a twisted pedicle. The question of an extra-uterine gestation was discussed, but the very definite statement by the patient as to the absolute regularity of the catamenia seemed against this. hypothesis. On March 14th the patient was markedly jaundiced, but by the 16th the jaundice had almost disappeared.

On March 18th I opened the abdomen in the middle line. below the umbilicus. The intestines in the lower part of the abdomen were much matted together. On separating the arlhesions much recent blood welled up and and a dark purple cyst-like swelling was exposed, which was recognised as an extra-uterine gestation sac. On incising the sac there was copious bleeding. The fotus was rapidly extracted and the blceding was checked by the pressure of the hand inside the sac. Further examination showed that the sac was incomplete, the roof of the cavity being formed of matted intestine. The placenta was attached to the posterior wall of the uterus and to the intestine. It was very friable and readily separated but the bleeding was profuse. The placental site was compressed by the hand, while the cavity was tightly packed with gavie. The foetation had apparently occurred in the right Fallopian tube which was ruptured close to the uterus. The pouch of Douglas was filled with recent uncIntted blood. There was some free recent blood in the flanks. After

1 A conmunication real at the G vnacolngical ancl Obstetrical Section of the Royal Society of Merlicine on Dec. 10th, 1908.

2 Transactions of the Oustetrical Society of Lomion, vol. xlvii, 1905, 